\title{
A brief insight on knowledge about Viral Hepatitis in Pregnancy among clinicians
}

Pranav Keshan $^{1}$, Sabin Syed ${ }^{2}$, Aayushi Rastogi $^{3}$, Akanksha Bansal $^{4}$

${ }^{1}$ Program Associate, Project ECHO, Institute of Liver and Biliary Sciences, New Delhi, India; ${ }^{2}$ Program Coordinator, Project ECHO, Institute of Liver and Biliary Sciences, New Delhi, India; ${ }^{3}$ PhD Scholar, Department of Epidemiology, Institute of Liver and Biliary Sciences, New Delhi, India; ${ }^{4}$ Senior Manager (Projects), Project ECHO, PRAKASH and LEAD, Institute of Liver and Biliary Sciences, India.

\begin{tabular}{|c|c|c|c|c|c|c|c|c|}
\hline Abstract & Introduction & Methodology & Results & Conclusion & References & Citation & \multicolumn{2}{|c|}{ Tables / Figures } \\
\hline \multicolumn{9}{|c|}{ Corresponding Author } \\
\hline \multicolumn{8}{|c|}{$\begin{array}{l}\text { Ms Akanksha Bansal, Senior Manager (Projects), Project ECHO, PRAKASH and LEAD, Institute of } \\
\text { Liver and Biliary Sciences, Vasant Kunj, Delhi - } 110070 . \\
\text { E Mail ID: abansal@ilbs.in }\end{array}$} & 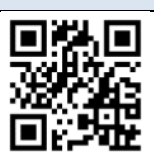 \\
\hline
\end{tabular}

\section{Citation}

Keshan P, Syed S, Rastogi A, Bansal A. A brief insight on knowledge about Viral Hepatitis in Pregnancy among clinicians. Indian J Comm Health. 2021;33(1):212-216. https://doi.org/10.47203/IJCH.2021.v33i01.031

Source of Funding: Nil Conflict of Interest: None declared

\section{Article Cycle}

\begin{tabular}{|c|}
\hline Received: 30/01/2021; Revision: 15/02/2021; Accepted: 05/03/2021; Published: 31/03/2021 \\
\hline This work is licensed under a Creative Commons Attribution 4.0 International License. \\
\hline
\end{tabular}

\section{Abstract}

Viral Hepatitis $(\mathrm{VH})$ is one of the most serious infections during pregnancy which not only creates complications for the mother but also transmits the infection to the newborn. Hence, clinicians should be aware about the diagnosis and management related to $\mathrm{VH}$ during pregnancy and modes to prevent it. Thus the present study aimed to assess the current knowledge about VH in pregnancy among clinicians. A cross-sectional study was conducted among physicians who attended National Seminar for Physicians on Viral Hepatitis in Pregnancy organized by PRAKASH. An online link to 25 -item questionnaire was circulated with all the registered participants. The data was analysed using IBM-SPSS version-21. The statistical significance was considered to be $<0.05$.A total of 64 physicians with mean age of $33.73 \pm 10.57$ were included in the study. Mean knowledge score was found to be $15.41 \pm 3.47$ out of 25 with 59\% of the participants having poor-to-moderate knowledge about VH in pregnancy. The study raises serious concerns about initiating training related to diagnosis and management of $\mathrm{VH}$ in pregnancy among clinicians.

\section{Keywords}

Viral Hepatitis, Pregnancy, Obstetrics and Gynaecology, Mother-To-Child-Transmission, Knowledge Assessment. Key Messages: Viral hepatitis is a severe complication during pregnancy and the knowledge level of physicians on management of viral hepatitis in pregnancy was poor to moderate. Thus, there is an urgent need to initiate trainings of clinicians on diagnosing and managing viral hepatitis during pregnancy.

\section{Introduction}

Viral hepatitis is a public health challenge affecting 325 million individuals globally. (1) World health organization (WHO) has estimated 9,00,000 deaths due to Hepatitis $B$ alone, due to cirrhosis and Hepatocellular carcinoma (HCC). (2) Of the five types of viral hepatitis, Hepatitis $B$ and Hepatitis $C$ are the most serious infections during pregnancy which not only prompts complications for the mother but can also be transmitted to the child during the course of pregnancy.(3)

Furthermore, $90 \%$ of the early acquired hepatitis B infection or infection acquired in infancy remains asymptomatic for decades and often results in chronic infection with life threatening complications such as liver cirrhosis and HCC. However, as the age 
increases, chances of chronicity of Hepatitis B decreases; thus chronicity of adult-acquired Hepatitis B infection is up to $5 \%$ only.(4) Thus, indicating early-acquired infection or infection among new-borns is the most common reason for chronic Hepatitis B, which is generally transmitted through vertical transmission, also known as mother-to-child-transmission (MTCT). Studies have shown MTCT occurs during prenatal (transplacental transmission in utero), natal (during delivery) as well as perinatal periods (during care or through breast milk) with maximum risk of transmission during perinatal period (70-90\%).(5) These incidences of perinatal HBV transmission can be drastically reduced by administration of immunoprophylaxis (HBIG) along with birth dose of HBV vaccine within 24 hours of delivery. Moreover, mothers with maternal HBeAg positive status and high level of HBV-DNA content ( $>8 \log 10$ copies/ml) have shown to transmit the infection among $9-39 \%$ of the infants despite postnatal active and passive immunization.(6)

In addition to HBV infection, presence of other hepatitis viruses can also complicate the pregnancy. Hepatitis $\mathrm{C}$ can also be transmitted through MTCT in $5 \%$ of the infants born to HCV-infected mothers with $60-80 \%$ chance to develop chronic infection among infected infants.(7) Hepatitis A infection during the third trimester is associated with increased risk of complications such as premature rupture of membrane, placental separation, or preterm labour.(8) Though hepatitis $E$ is generally a selflimiting condition in majority of cases, however during pregnancy, it can cause acute liver failure and also results in maternal fatality in $16-20 \%$ cases. $(9,10)$ Further, it is important for the gynaecologist or the treating physician to be aware about the status of the pregnant females and available treatment modalities to prevent MTCT. However, there is limited information about the knowledge status of physicians related to viral hepatitis in pregnancy. The present study aims at assessing the current knowledge among clinicians with respect to diagnosis and management of viral hepatitis in pregnancy.

\section{Aims \& Objectives}

1. To assess the current knowledge among clinicians with respect to diagnosis and management of viral hepatitis in pregnancy.
2. To explore the demographic factors associated with current knowledge related to diagnosis and management of viral hepatitis in pregnancy.

\section{Material \& Methods}

A cross-sectional study was conducted among gynecologists and physicians who attended the National Seminar for Physicians on Viral Hepatitis in Pregnancy organized by the project PRAKASH (PRogrammed Approach to Knowledge and Sensitization on Hepatitis), Institute of Liver and Biliary Sciences, New Delhi on the occasion of viral hepatitis day (July 27, 2020). The participants were either faculty members or physicians involved in providing maternal care.

An online link to SurveyMonkey was shared with all the registered participants for assessing their knowledge about viral hepatitis in pregnancy. The first page of the online questionnaire, consisted of consent form which clearly stated about the background and objectives of the study.

The questionnaire consisted of two section. Section A included demographic details whereas section B included 25-multiple choice knowledge related questions. Participants were awarded one mark for every correct response and zero mark for incorrect response. The questions in the knowledge assessment questionnaire were broadly divided into three domains: i) general awareness on viral hepatitis, ii) acute hepatitis during pregnancy and iii) chronic hepatitis during pregnancy. General awareness on viral hepatitis domain included Q5, Q7, Q8, Q9, Q14, Q20, Q22, Q23, Q24,Q25 whereas domain related to acute hepatitis in pregnancy included Q1, Q2, Q4, Q6, Q13, Q16, Q17, Q19 and Q3, Q10, Q11, Q12, Q15, Q18, Q21 were grouped under domain of chronic hepatitis in pregnancy. Based on the above scoring, the maximum score allotted to domain one was ten, domain two was eight and domain three was seven (Supplementary 1).

Knowledge score was further divided into good and poor-to-moderate. The knowledge score was consider to be good if the score was more than or equal to 17 (66.6\% of the total score) whereas the knowledge score was considered poor-to-moderate if the score was below 17.(11)

The data of knowledge assessment of the participants was extracted in MS-Excel from SurveyMonkey and was analyzed using IBM-SPSS version-21. Personal details of the participants like 
name, mobile number and email ids were delinked from the final data sheet and unique ID were allotted for maintaining confidentiality of the participants. The continuous data was presented as mean and standard deviation whereas categorical data was presented as frequencies with percentages. For the purpose of analysis, age was divided into two groups as (i) less than 30 years and (ii) 30 years and above.(12) For better understanding of knowledge among clinicians, departments were grouped into two categories as (i) Obstetrics and Gynaecology and (ii) other than Obstetrics and Gynaecology. Independent samples t-test was used to assess the mean knowledge score across various demographic factors. The statistical significance was fixed as conventional $p$-value of 0.05 (two-tailed).

The present study is lying under less than minimum risk as per latest National Ethical Guidelines for Biomedical and Health Research Involving Human Participants and study used anonymous data, thus ethical clearance was not obtained from the Institute ethics committee before collecting the data.(13) However, permission was taken from institute for analyzing the data.

\section{Results}

A total of 64 physicians with mean age of $33.73 \pm 10.57$ years participated in the assessment of knowledge. Out of total participants, 27 (42.2\%) were females and approximately $64 \%$ of the participants were post-graduate and above. Based on their specialization, 24 (37.5\%) participants were working in obstetrics and gynaecology department and remaining 40 (62.5\%) were working in other departments. The participants were from eight States/Union territories but majorly from Delhi (57.8\%).

Among them the mean knowledge assessment score was found to be $15.41 \pm 3.47$, out of total score of 25 . A total of 38 (59.3\%) participants fell in the poor-tomoderate category whereas the remaining 26 $(41.7 \%)$ belonged to good knowledge category. Domain wise mean knowledge score was found to be $6.47 \pm 1.64$ for general awareness on viral hepatitis, $5.30 \pm 1.71$ for questions on acute hepatitis during pregnancy, whereas mean knowledge score for question related to chronic hepatitis during pregnancy was $3.64 \pm 1.46$. The correct responses in the knowledge assessment questionnaire was found to be ranging from $23 \%$ to $97 \%$ and a total of $61.6 \%$ physicians responded correctly (Supplementary 1 ).
The association of knowledge score and demographic factors suggested that the mean knowledge score among clinicians less than 30 years of age was $14.94 \pm 3.77$ whereas the score was $15.88 \pm 3.13$ among physicians of 30 years and above $(p=0.284)$. The mean knowledge score among males and females were $15.30 \pm 3.21$ and $15.56 \pm 3.86$ respectively indicating no difference in knowledge related to viral hepatitis with respect to gender $(p=0.771)$. However, both these associations were not found to be significant. Further, on comparison of various categories of education level, i.e. graduates and post-graduates, it was found that knowledge score had no significant association with education $(p=0.902)$. Similar to other demographic factors, there was no variations observed in knowledge levels with respect to their current working department $(p=0.783)$. (Table 1)

\section{Discussion}

Viral hepatitis infection is the most serious infection that not only creates complications for the mother but also transmits the infection to the newborn. Hence, the treating physicians should be aware about the diagnosis and management related to viral hepatitis during pregnancy and modes to prevent it. Thus the study assessed the knowledge among clinicians with respect to diagnosing and management related to viral hepatitis in pregnancy. The study suggested that treating physicians and gynecologist had a mean knowledge score of $15.41 \pm 3.47$ with $59.3 \%$ of the physicians falling in poor-to-moderate category with respect to knowledge related to viral hepatitis. The knowledge score of the present study could not be compared with any other existing studies as the present study was first of its kind. However, the knowledge in this novel study when compared with few components of existing studies was found to be lower among the physicians as the previous studies included basic questions related to screening and immunoprophylaxis among infants, whereas the current study included detailed questions related to viral hepatitis in pregnancy, focusing on diagnosis as well as management of viral hepatitis in pregnancy.(14)

The study further highlighted that the knowledge regarding general and acute hepatitis was better as compared to chronic hepatitis, which can be attributable to the asymptomatic nature of chronic hepatitis. It was found that the physicians were well 
aware about the transmission and prevention about the viral hepatitis as they would have studied about it during their medical education. Further acute hepatitis is accompanied with several symptoms like jaundice, abdominal pain, yellowing of urine, which generally can't be ignored and require immediate treatment. However, chronic hepatitis is asymptomatic and goes unnoticed because of absence of its immediate effect. Though it's asymptomatic, it requires immediate set of actions for prevent complication during natal and post natal period.

The present study found that there was no difference in knowledge of viral hepatitis with respect to demographic variables. This is mainly attributable to the ignorance and less importance given to viral hepatitis among physicians especially in developing countries.(15) It could also be attributable to the fact that the study was conducted in small sample and hence possibly was unable to detect any significant difference in knowledge score with respect to the demographic factors.

Despite being a small study, the present study is an important contribution to field of viral hepatitis awareness as it highlights the poor to moderate knowledge among clinicians associated with maternal care. The study suggests that an immediate action should be taken to initiate the training regarding diagnosing and managing viral hepatitis in pregnancy among treating physicians. This will help in further planning interventions to prevent viral hepatitis transmission and also managing the complications associated with it.

\section{Conclusion}

The study concludes poor-to-moderate knowledge among treating physicians and gynecologist with respect to knowledge related to viral hepatitis in pregnancy. The study also emphasizes better knowledge regarding general and acute hepatitis as compared to chronic hepatitis. Thus, there is a need to train these physicians related to diagnosis and management related to viral hepatitis in pregnancy.

\section{Recommendation}

The study recommends an immediate action should be taken to initiate the training regarding diagnosing and managing viral hepatitis in pregnancy among treating physicians. This will help in further planning interventions to prevent viral hepatitis transmission and also managing the complications associated with it.

\section{Limitation of the study}

The limitation of the study is its small sample size. Secondly, the questionnaire used for assessing the knowledge is not a pre-validated tool, however, it has been content validated from experts, prior to initiating data collection.

\section{Relevance of the study}

The study highlights the need for training physicians related to diagnosis and management of viral hepatitis in pregnancy as there is poor-to-moderate knowledge among treating physicians and gynecologists.

\section{Authors Contribution}

$A B$ conceptualized the study. Data collection was supervised by $A B$ and $S S$. Data analysis was carried out by PK and AR. First draft of the manuscript was written by PK. Draft was reviewed and revised by all authors.

\section{Acknowledgement}

Authors are grateful to CIPLA foundation, for providing financial support to Project PRAKASH under its corporate social responsibility policy. Authors are thankful to Dr S.K.Sarin, Director Institute of Liver and Biliary Sciences, for providing his valued guidance and continuous support. Authors also extend our gratitude to the faculty of Institute of Liver and Biliary Sciences for their endless support.

\section{References}

1. World Health Organisation. GLOBAL HEALTH SECTOR STRATEGY ON VIRAL HEPATITIS [Internet]. 2016;Available from:

https://apps.who.int/iris/bitstream/handle/10665/246177 LWHO-HIV-2016.06-

eng.pdf;jsessionid=560954C2BB155AB3FF0B2191DB7FE47 9? sequence=1 [Accessed on 02 Feb 2021]

2. Hutin Y, Desai S, Bulterys M. Preventing hepatitis B virus infection: milestones and targets. Bull World Health Organ. 2018;96(7):443-443A. doi: 10.2471/BLT.18.215210. PMID: 29962544; PMCID: PMC6022619.[PubMed].

3. Navabakhsh B, Mehrabi N, Estakhri A, Mohamadnejad M, Poustchi H. Hepatitis B Virus Infection during Pregnancy: Transmission and Prevention. Middle East J Dig Dis. 2011;3(2):92-102. PMID: 25197539; PMCID: PMC4154922.[PubMed]

4. World Health Organisation. PREVENTION OF MOTHER-TOCHILD TRANSMISSION OF HEPATITIS B VIRUS: GUIDELINES ON ANTIVIRAL PROPHYLAXIS IN PREGNANCY. 2020;Available from: https://apps.who.int/iris/bitstream/handle/10665/333391 /9789240002708-eng.pdf?sequence=1\&isAllowed $=\mathrm{y}$

5. Hou J, Liu Z, Gu F. Epidemiology and Prevention of Hepatitis B Virus Infection. Int J Med Sci. 2005;2(1):50-57. doi: 
10.7150/ijms.2.50. Epub 2005 Jan 5. PMID: 15968340; PMCID: PMC1142225.[PubMed]

6. Wiseman E, Fraser MA, Holden S, Glass A, Kidson BL, Heron LG, Maley MW, Ayres A, Locarnini SA, Levy MT. Perinatal transmission of hepatitis $B$ virus: an Australian experience. Med J Aust. 2009;190(9):489-92. doi: 10.5694/j.13265377.2009.tb02524.x. PMID: 19413519.[PubMed]

7. Resti M, Azzari C, Mannelli F, Moriondo M, Novembre E, de Martino $M$, Vierucci A. Mother to child transmission of hepatitis $C$ virus: prospective study of risk factors and timing of infection in children born to women seronegative for HIV-1. Tuscany Study Group on Hepatitis C Virus Infection. BMJ. 1998;317(7156):437-41. doi: 10.1136/bmj.317.7156.437. PMID: 9703524; PMCID: PMC28636.[PubMed].

8. Kwon H, Lok AS. Viral hepatitis and pregnancy. Clin Liver Dis (Hoboken). 2014;4(3):55-57. doi: 10.1002/cld.367. PMID: 30992921; PMCID: PMC6448734.[PubMed]

9. Tsega E, Krawczynski K, Hansson BG, Nordenfelt E. Hepatitis $\mathrm{E}$ virus infection in pregnancy in Ethiopia. Ethiop Med J. 1993;31(3):173-81. PMID: 8404882.[PubMed]

10. Lockwood GL, Fernandez-Barredo S, Bendall R, Banks M, ljaz S, Dalton HR. Hepatitis $E$ autochthonous infection in chronic liver disease. Eur J Gastroenterol Hepatol.
[Viral Hepatitis in...] | Keshan P et al 2008;20(8):800-3. doi: 10.1097/MEG.0b013e3282f1cbff. PMID: 18617787.[PubMed].

11. Anwar MM, Khalil DM. Breast cancer knowledge, attitude and practice among medical and non-medical university students. J Public Health. 2020;Available from: https://doi.org/10.1007/s10389-020-01197-z [Accessed on 02 Feb 2021]

12. Bhardwaj T, Tandon S, Chand S, Bhargava A. Knowledge, attitude and practice towards preventive dental care- A KAP study. J Glob Oral Health. Available from: https://doi.org/10.25259/JGOH 342019

13. INDIAN COUNCIL OF MEDICAL RESEARCH. National Ethical Guidelines For Biomedical And Health Research Involving Human Participants. 2017;Available from: https://ethics.ncdirindia.org//asset/pdf/ICMR National Et hical Guidelines.pdf

14. Ferrante JM, Winston DG, Chen PH, de la Torre AN. Family physicians' knowledge and screening of chronic hepatitis and liver cancer. Fam Med. 2008;40(5):345-51. PMID: 18465284.[PubMed]

15. Muralidhar S, Singh PK, Jain RK, Malhotra M, Bala M. Needle stick injuries among health care workers in a tertiary care hospital of India. Indian J Med Res. 2010;131:405-10. PMID: 20418554. [PubMed].

\section{Tables}

TABLE 1 ASSOCIATION OF KNOWLEDGE ASSESSMENT WITH DEMOGRAPHIC CHARACTERISTICS

\begin{tabular}{|c|c|c|}
\hline Variable & Mean score \pm SD & p Value \\
\hline Age & & \\
\hline $\begin{array}{l}\text { Less than } 30 \text { years } \\
30 \text { years and more }\end{array}$ & $\begin{array}{l}14.94 \pm 3.77 \\
15.88 \pm 3.13\end{array}$ & 0.284 \\
\hline $\begin{array}{l}\text { Gender } \\
\text { Male } \\
\text { Female }\end{array}$ & $\begin{array}{l}15.30 \pm 3.21 \\
15.56 \pm 3.86\end{array}$ & 0.771 \\
\hline $\begin{array}{l}\text { Qualification } \\
\text { Graduate } \\
\text { Post-graduate }\end{array}$ & $\begin{array}{l}15.48 \pm 3.06 \\
15.37 \pm 3.72\end{array}$ & 0.902 \\
\hline $\begin{array}{l}\text { Department } \\
\text { Obstetrics and Gynaecology } \\
\text { Other than Obstetrics and Gynaecology }\end{array}$ & $\begin{array}{l}15.25 \pm 2.97 \\
15.50 \pm 3.78\end{array}$ & 0.783 \\
\hline
\end{tabular}

